\title{
Biotech shares fall as company halts asthma drug trials
}

Oxford. Britain's burgeoning biotechnology sector lost some of its gloss last week when Celltech, one of its most well-established companies, announced it was halting trials with CDP840, a potential asthma drug from a class of drugs known as selective phosphodiesterase IV inhibitors (PD IV).

The value of Celltech's shares on the London Stock Exchange dropped by more than 25 per cent immediately following the news, and the slippage then continued. The shares of other British biotechnology stocks fell in sympathy.

Celltech and its partner, Merck Sharp and Dohme, the US pharmaceuticals company, decided to halt the phase II trial, which identifies the effectiveness of a drug against a target disease, because CDP840's performance did not match expectations.

"In collaboration with Merck we identified a number of desirable properties a new asthmatic treatment should have," explains David Bloxham, chief executive of Celltech Therapeutics. "It should be orally active, have anti-inflammatory activity and be able to prevent rapidly the initial contraction of air pipes that causes asthma."

The two companies were hoping to develop a product combining the rapid relief of symptoms associated with beta agonists such as salbutamol with the long-term antiinflammatory activity of the steroid drugs at present prescribed to asthmatics.

"While the phase II trial demonstrated that CDP840 is orally absorbed, safe and had anti-inflammatory activity, it did not provide the desired rapid onset or relief," Bloxham adds. "To have a new asthma medicine that can be taken orally is not enough in these cost-conscious times."

Celltech's action reflects the desire of most biotechnology companies to axe potential new products as early as possible in the development programme if they do not meet projected goals; more than 80 per cent of the costs involved in developing a new medicine are associated with phase III clinical trials and beyond.

Indeed, products that get as far as phase II still have only a 50 per cent chance of reaching the market. But when a product is abandoned, the investment community tends to use this to judge a company's performance, as it has little other information on which to base an assessment.

Although Celltech's decision may be the end of the road for the CDP840 molecule, it is not necessarily the end of PD IV as an asthma therapy. Bloxham claims that CDP840 has provided both Celltech and Merck with information that they plan to use in the design of newer PD IV molecules. Mike Ward

\section{'Fraud police' face dilemma over warning medical boards}

San Diego. Officials from the US Department of Health and Human Services (HHS) have said they will discuss whether medically qualified researchers who admit to fabricating research data should be automatically reported to the state-run bodies that issue licences to practise medicine.

This follows evidence of at least one case in which such information was not passed on by the National Institutes of Health's Office of Research Integrity (ORI). According to ORI officials, this was partly out of concern that any such ruling would discourage researchers from admitting their guilt, thus increasing the workload on the office, and delaying the consideration of other cases.

The case involves a former research fellow in obstetrics and gynaecology at the University of California at San Francisco (UCSF), James T. Kurtzman, who admitted in 1993 to fabricating data on nitric oxide levels used to measure uterine function.

Following an investigation by officials from UCSF and the National Institutes of Health (NIH), which funded the research, Kurtzman left San Francisco quietly in 1994, eventually agreeing to a penalty under which he was barred for three years from involvement in federally funded research.

The agreement, which was reached last year between Kurtzman and the ORI, specifically states that Kurtzman's admission to falsifying research would not be used to prevent him from practising medicine. But board officials who, as a result, were not made aware of his misconduct are upset.

"We want to know about cases like these," says Candis Cohen, a spokeswoman for the Medical Board of California which, like similar bodies in other states, can impose penalties that can include revoking the licence of physicians found to have engaged in scientific misconduct.

Lyle W. Bivens, director of ORI, acknowledges that state medical boards are keen to learn about cases of scientific misconduct that may raise questions about the integrity of licensed physicians. But he says that, as a rule, his agency does not notify the board. "We wouldn't get voluntary exclusion agreements if we pulled the rug out from under a person's livelihood," says Bivens.

"This is a tough issue," he admits. "It is one we haven't struggled with." Whether someone who admits to having taken short cuts or fabricated research results is inevitably a bad physician "is not a judgement we can or should make," says Bivens. "But it does beg the question of whether medical boards should be notified."

Arthur J. Lawrence, a senior adviser in the office of the assistant secretary of the HHS, which would be responsible for draw- ing up any federal guidelines on the issue, admits that Kurtzman's cases "poses a real interesting question". He says that HHS attorneys will review the issue.

Some researchers believe that colleagues who admit to fraud should be reported to medical authorities. These include R. Kirk Riemer, who headed the UCSF research project and says that over two years of his work were ruined by Kurtzman. "It's wrong to even consider that this behaviour is not going to carry over to other aspects of life, professional or private," said Riemer.

Insisting that he has since tried to "take the high road", Kurtzman describes the episode as "the most painful thing in my life". He now teaches in a UCSF-affiliated residency programme at a community hospital in Salinas, where he was recently given a teaching honour and a community service award for treating the poor.

But in California, as in many other states, hospitals must report physicians who leave their medical staff while under investigation. Kurtzman said that UCSF did not report him to the medical board. Karl J. Hittelman, an associate vice chancellor at the medical school, says that universities are caught between laws that require reporting of such events and the possibility of being sued for limiting a physician's livelihood.

"Whether intellectual dishonesty at the research bench can be assumed to have an implication for medical practice is a complex issue that is saturated with legal ramifications," said Hittelman. "At a personal level, it sends up a flashing yellow light in my brain. But it needs to be addressed on a case-by-case basis."

Medical board officials agree - but say that it is precisely for this reason that they are keen to be notified of such cases. California is already considering what to do in the case of Anand Tewari, who was barred in 1994 from receiving federal research funds for five years after he was found to have fabricated research results while a fellow in surgery at Stanford.

According to federal records, Tewari signed an agreement with ORI similar to Kurtzman's, in which he acknowledged faking laboratory results on a number of patients in a drug study, but both sides agreed that this should not affect his ability to practise medicine.

In this case, however, Stanford notified the medical board, which in September filed an challenge to Tewari's medical licence, alleging dishonesty and gross negligence for the research misconduct. A state hearing is to be held to decide whether Tewari, who could not be reached for comment, should be punished in any way.

Rex Dalton 